\title{
DESKRIPTIF PENGGEMBALAAN YANG SEHAT MENURUT KITAB TITUS TERHADAP PERTUMBUHAN JEMAAT GPSI WILAYAH I
}

\author{
Riana Udurman Sihombing ${ }^{1)}$ Rahel Rati Sarungallo ${ }^{2)}$ \\ 1) Sekolah Tinggi Teologi Injili Indonesia - Samarinda \\ E-mail:riana_sihombing@yahoo.com2) \\ 2) Sekolah Tinggi Teologi Injili Indonesia - Samarinda \\ E-mail: rahelratisarungallo@gmail.com
}

\begin{abstract}
The growth of a church is not instant. Expected growth cannot be separated from the influence of comprehensive teaching from a pastor and other instructors, the true growth process of the Church is inseparable from a way that is through discipleship, so that the congregation that he pastors may grow in quality and quantity to lead to the expected maturity by Christ.

In fact in the church where the researchers joined, namely GPSI Shekinah Samarinda, the Assumption found several problems regarding the commitment of the congregation in GPSI Region I Samarinda. A temporary assumption is that not a few local church congregations do not reside or in other words like to move around church denominations.

This is a sign that there is a problem with the so-called effect of a healthy shepherding on the growth of local congregations. This temporary assumption needs to be explored more depth in what causes and how local church congregations who are supposed to comply with local church rules, in fact do not implement and have no commitment to the local church.
\end{abstract}

Keywords: Pastoral, Healthy, Growth, Church

\section{LATAR BELAKANG MASALAH}

Pertumbuhan jemaat merupakan impian setiap hamba Tuhan maupun jemaat, karena pertumbuhan itu sendiri merupakan tuntutan dari Allah. Disebut bertumbuh adalah berbeda dari awal, ada kemajuan dan perkembangan yang mengarah kepada kedewasaan, bukan stagnan yang hanya berjalan di tempat yang tidak memperlihatkan buahnya sebagai bukti kedewasaannya, sebagaimana yang dikatakan dalam Kol 2:6-7 kamu telah menerima Kristus jesus Tuhankita. karena itu hendaklah hidupmu tetap didalam dia. Hendaklah kamu berakar didalam Dia dan dibangun di atas Dia. Hendaklah kamu bertambah teguh dalam iman yang telah diajarkan kepadamu. Dan hendaklah hatimu melimpah dengan syukur.

Perbincangan yang hangat di kalangan gereja Tuhan. Pertumbuhan yang sehat yang dihasilkan oleh penggembalaan yang baik merupakan Hal yang dinantikan oleh setiap umat Tuhan, Namun, pertumbuhan gereja bagaimanakah yang disebut sebagai gereja sehat? Memiliki gedung gereja yang besar dengan jumlah anggota jemaat yang banyak adalah kerinduan setiap hamba Tuhan maupun semua orang percaya.

Namun pertumbuhan gereja yang sehat bukan hanya dinilai dari kuantitas saja tetapi juga dari kualitas, karena kualitas menentukan kuantitas, bukan kuantitas menentukan kualitas.

Inilah yang menjadi dasar bahwa setiap orang percaya yang telah menerima Yesus sebagai Tuhan dan Juru Selamat perlu bertumbuh secara dinamis seperti yang diungkapkan Paulus kepada jemaat Kolese

Kamu telah menerima Kristus Yesus, Tuhan kita. Karena itu hendaklah hidupmu tetap di dalam Dia. Hendaklah kamu berakar di dalam Dia dan dibangun di atas Dia, hendaklah kamu bertambah teguh dalam iman yang telah diajarkan kepadamu, dan hendaklah hatimu melimpah dengan syukur. Pertumbuhan sebuah jemaat tidaklah instan. Pertumbuhan yang diharapkan tidak lepas dari pengaruh dari pengajaran yang secara 
komprehensif dari seorang gembala sidang dan pengajar lainnya, proses pertumbuhan Gereja yang benar tidak lepas dari sebuah cara yaitu melalui pemuridan, sehingga jemaat yang di gembalakannya boleh bertumbuh secara kuailitas dan kuantitas untuk mengarah kepada kedewasaan yang diharapkan oleh Kristus.

Alkitab adalah landasan yang harus dipakai seorang Gembala Sidang sekaligus sebagai pengajar, seorang pengajar yang baik harus mampu mengembangkan pengajarannya berdasarkan Alkitab. Berarti seorang Gembala sekaligus pengajar harus mampu mengembangkan pengajarannya.

Untuk mencapai sebuah pertumbuhan Gereja perlu membawa orang-orang yang tidak memiliki hubungan pribadi dengan Yesus Kristus kedalam persekutuan dengan Dia dan membawa mereka menjadi anggota gereja yang bertanggungjawab. Untuk itu, kekristenan sangat mendambakan seoreng Gembala yang memiliki pengajaran yang sehat di setiap Gereja Lokal bahkan di tengah organisasi yang terdiri dari berbagai tingkat pemahaman teologis yang berbeda-beda.

Kualitas penggembalaan adalah hal yang sangat penting karena menyangkut keselamatan seluruh jemaat yang dipimpinnya. Penggembalaan bukan hanya sekedar mengumpulkan orang datang beribadah namun penggembalaan harus bertanggung jawab atas keselamatan setiap jemaat yang dipimpinnya, sekalipun hal itu tidak dicapai dengan waktu yang singkat. Menurut Ralph M.Riggs mengenai gembala yang berhasil bukanlah instan Menjadi Gembala sidang yang berhasil merupakan pekerjaan terbesar yang mungkin dalam hidup ini. Hal itu tak akan tercapai dengan hanya satu jam penyerahan dihadapan Allah, atau satu malam bergumul dalam doa, atau usaha yang singkat, meskipun dengan bersungguh-sungguh. Bangunan yang besar memerlukan perencanaan yang teliti dan penggalian yang dalam. Karir yang berhasil, mula-mula memerlukan kemampuankemampuan tertentu dan minat yang kuat [1] Maksudnya setiap gembala sidang harus sadar bahwa penggembalaan yang berhasil tidak datang dengan sendiri dan tidak mudah untuk mencapainya, harus diikuti kerajinan dan pemahaman teologis yang memadai.

Seth Msweli mendefinisikan penggembalaan sebagai berikut, "Seorang gembala sidang harus mengetahui bahwa ia telah diselamatkan. Akan tetapi, beberapa
Gembala Sidang tidak yakin akan keselamatannya"[2] Yesus pernah berkata dalam Matius 15:14 jika orang buta menuntun orang buta, pasti keduanya masuk lobang. artinya seorang Gembala Sidang atau yang memimpin jemaat harus mengerti benar tentang Alkitab secara konprehensif supaya dapat memimpin Jemaat kepada kebenaran.

Berdasarkan pengamatan ini, maka penulis akan memberikan gambaran melalui penelitian ini secara keseluruhan. Masalah terbesar dalam pelayanan penggembalaan adalah ketika seorang gembala menyerongkan ajaran yang tidak berlandaskan kepada firman Tuhan.

Seorang Gembala seharusnya memiliki kompetensi yang baik, ketika terjun kedunia penggembalaan supaya mengerti benar kebutuhan umat yang digembalakannya.Sebagai mana tujuan Paulus meninggalkan Titus di pulau Kreta yaitu untuk membangun iman Jemaat yang ada di pulau Kreta.

Sehubungan dengan itu seorang Gembala Sidang diharuskan memiliki persyaratan-persyaratan tertentu yang akan dipakai untuk membina umat Allah sebab sebagai Gembala tidak hanya sekedar mengumpulkan jemaat namun membimbing dan mengarahkan kepada kebenaran yang hakiki.

Setelah manusia menerima Yesus sebagai Tuhan dan Juruslamat satu-satunya Secara Pribadi maka orang percaya itu harus terus bertumbuh secara terus menerus. Pertumbuhan Rohani adalah hal yang sangat penting, batasan iman Kristen bukan hanya sampai pada tingkat percaya pada Yesus Kristus sebagai Tuhan dan Juruselamat tetapi ada pertumbuhan iman yang secara terus menerus sehingga menjadi serupa dengan Kristus. Dalam buku pemuridan One to One menjelaskan bahwa:

Pertumbuhan adalah sebuah proses yang harus di tempuh langkah demi langkah oleh seseorang supaya bertumbuh menjadi dewasa secara rohani di dalam kristus. Setiap orang punyai kepribadian dan kebutuhan yang berbeda. Maka jalan yang ditempuh hendaknya luwes dan disesuaikan dengan kebutuhan setiap orang.[3] Berdasarkan pengamatan penulis, ada beberapa sumber masalah yang menyebabkan pertumbuhan jemaat tidak berjalan secara tidak sehat. 
Beberapa hal tersebut adalah terdapat pada para Gembala.

Fenomena yang terjadi di dalam gereja lokal adalah kurangnya pengetahuan teologi para gembala. Hal ini tentu berpengaruh terhadap setiap pengajaran yang disampaikan, menyebabkan terjadinya pengajaran yang tidak sesuai firman Tuhan, seperti penggabungan antara teologi dan okultisme, pengajaran yang berfokus kepada kemakmuran, dan lain-lain.

Sumber masalah tersebut di atas jugalah yang menyebabkan jemaat tidak diberikan makanan sehat atau pengajaran yang koprehensif untuk pertumbuhan rohani. Ketidakpuasan terhadap pengajaran yang tidak sehat, menyebabkan ada jemaat yang datang dan pergi sesuka hati.

Adapun permasalahan yang melatar belakangi penulis dalam pembahasan tentang kajian teologis penggembalaan yang sehat menurut kitab Titus dan relevansinya terhadap pertumbuhan jemaat adalah:

1.Gereja adalah tempat perkumpulan orangorang yang percaya kepada Yesus sebagai Tuhan dan Juru Selamat. Melalui komunitas ini sangat memiliki kesempatan untuk mengajarkan pengajaran yang komprehensif dari seorang Gembala Sidang yang memiliki pengetahuan akan Firman Allah untuk pertumbuhan jemaat yang di pimpinnya. Titus adalah seorang pemimpin yang ditetapkan oleh Tuhan melalui Paulus. Bertugas untuk memilih dan menetapkan penatua yang sesuai standar Alkitab untuk melayani disetiap gereja lokal, mengingat banyaknya pengajaran -pengajaran yang palsu di sekitar umat Tuhan.

\section{PERTUMBUHAN JEMAAT}

Pertmbuhan jemaat dapat juga diselidiki bagaimana jemaat tetap bertahan dan samasama melayani bekerja sama dengan Gembala sidangnya ketika jemaat itu tidak memperoleh pengajaran / pendidikan yang sistematis dari Gembalanya.

Ronald W. Leigh menjelaskan dalam bukunya sebagai berikut:

Apakah syarat-syarat yang harus dipenuhi seorang pekerja Kristen? Yang jelas ia harus benar-benar orang Kristen. Ia harus paling tidak sudah tampak bertumbuh dalam banyak bidang kehidupannya dan terus bertumbuh secara rohani. Ada dua bidang pertumbuhan yang tampaknya amat penting dalam terang arti Alkitab dan Rohkudus,seperti yang dibicarakan dalam prinsip 1. Pertama, ia harus menguasai ajaranajaran Alkitab dengan baik. Hal ini tidak berarti bahwa ia harus menjadi sebuah ensiklopedi Alkitab berjalan; tapi ia harus cukup mengenal Perjanjian Lama dan Baru, mengetahui dengan tepat penafsiran ajaranajaran Alkitab yang utama, dan memiliki pandangan yang terpadu baik mengenai Allah, manusia dan kehidupan. Paulus berkata kepada Timotius, sang pendeta muda, untuk menjadi orang yang "berterus terang memberitakan perkataan kebenaran itu"(2Tim 2:15).

Kedua, ia harus hidup sesuai dengan apa yang diketahuinya. Ia harus secara konsisten memberikan teladan tentang kehidupan Kristen yang muncul dari penerapan akan ajaran-ajaran Alkitab didalam kuasa rohkudus. Paulus berkata kepada Titus, sang pendeta muda itu,"jadikanlah dirimu sendiri suatu teladan dalam berbuat baik"(Titus 2:7).'"[4] Berdasarkan kenyataan di atas, maka surat penggembalaan Titus pasal 1-3 menjadi salah satu sumber yang penting dalam membuat kajian tentang pengaruh penggembalaan yang sehat terhadap pertumbuhan Jemaat. Atas dasar itulah maka peneliti akan membuat kajian secara mendalam tentang pokok bahasan yang sesuai dengan penelitian ini.

Maka surat Titus pasal 1-3 merupakan surat penggembalaan yang menjadi dasar tinjauan teologis dari penelitian ini untuk menemukan karakteristik penggembalaan yang sehat yang mempengaruhi pertumbuhan kualitas dan kuantitas serta komitmen jemaat di gereja lokal.

Tetapi kamulah bangsa yang terpilih, imamat yang rajani, bangsa yang kudus, umat kepunyaan Allah sendiri, supaya kamu memberitakan perbuatan-perbuatannya yang besar dari Dia, yang telah memanggil kamu keluar dari kegelapan kepada terang-Nya yang ajaib' [5] Penggembalaan yang sehat merupakan awal dari pertumbuhan jemaat, hal ini merupakan suatu rencana Allah. Allah menghendaki supaya pertumbuhan semakin berkembang dan mengakar kepada iman yang murni.

Kehadiran penggembalaan yang sehat memegang peranan penting dalam pertumbuhan iman jemaat dan sebagai wadah 
dalam melakukan fungsi sebagai Tubuh Kritus. Dalam Alkitab terdapat Gereja yang sehat dibentuk melalui pendidikan dari Gembala Sidang sebagai orang pertama yang bertanggungjawab.

Dari gereja yang sehat maka muncullah sebuah komitmen di hati jemaat untuk bertahan karena merasa imannya bertumbuh dan kebutuhan spritualnya tercukupi sehingga Jemat merasakan pertumuhan dan mersa Gembalanya masih tetap disenangi, hal ini disetujui oleh warren W dan David "Pak pendeta, Jemaat menyukai anda dan menginginkan Anda

Peneliti beranggapan bahwa keberadaan jemaat di bawah pengawasan gembala setempat amatlah penting sebab dengan demikian kehidupan jemaat semakin dapat di gembalakan dan diarahkan kepada pengenalan kehendak Sang Kepala Gereja yaitu Yesus Kristus, sebab kelemahan jemaat diibaratkan seperti domba yang sering tersesat, "Kita sekalian sesat seperti domba, masing-masing mengambil jalannya sendiri."

Jemaat yang setia sebagai anggota gereja di sebuah gereja lokal, cenderung memiliki sikap dan perilaku rohani yang lebih seimbang dari jemaat yang tidak menetap di sebuah gereja lokal.

Pada kenyataannya di gereja di mana peneliti bergabung yaitu GPSI Shekinah Samarinda, Asumsi sementara mendapati beberapa permasalahan tentang komitmen jemaat di GPSI Wilayah I Samarinda. Asumsi sementara yang di temui bahwa tidak sedikit jemaat gereja lokal yang tidak menetap atau dengan kata lain suka berpindah-pindah denominasi gereja.

Hal ini menjadi pertanda bahwa ada masalah dengan yang dinamakan pengaruh penggembalaan yang sehat terhadap pertumbuhan jemaat lokal. Asumsi sementara ini perlu digali lebih dalam apa penyebab dan bagaimana jemaat gereja lokal yang seharusnya tunduk pada aturan gereja lokal, justru tidak melaksanakan dan tidak memiliki komitmen terhadap gereja lokal.

Dengan latar belakang tersebut di atas, maka penulis menyimpulkan bahwa ada masalah di dalamnya yang tidak seirama dengan penggembalaan yang sesuai perspektif teologi Paulus.

\section{RUMUSAN MASALAH}

Berdasarkan identifikasi masalah tersebut, maka penulis mengajukan pertanyaan:

1. Apakah ada pengaruh penggembalaan yang sehat bagi pertumbuhan GPSI wilayah I ?

2. Sejauh mana pengaruh penggembalaan yang sehat di GPSI Wilayah I. ?.

\section{TUJUAN PENELITIAN}

Mengingat pentingnya fungsi penggembalaan terhadap pertumbuhan jemaat yang bersumber dari kebenaran firman Tuhan dan setelah memahami permasalahan yang ada maka penulis menjelaskan beberapa hal yang menjadi tujuan penulisan tesis ini

Pertama: penulis ingin supaya prinsipprinsip penggembalan yang Alkitabiah yang sesuai dengan surat Titus 1-3 dapat diteladani oleh Gembala Sidang masa kini sehingga pola penggembalaan mereka memiliki terobosan yang bisa membawa kepada keberhasilan sesuai tuntutan surat Titus.

Kedua: Untuk dapat memahami tentang penggembalaan yang berhasil tersebut maka penulis dalam bagian ini akan menjelaskan tentang integritas seorang Gembala Sidang, yaitu dimulai dari pemahamannya akan firman Tuhan secara komprehensif dan syarat-syarat menjadi seorang gembala sidang.

Ketiga: Dengan ditemukannya syaratsyarat tersebut sesuai dengan Surat Titus1-3 yaitu sebagai fakta kebenaran yang telah dianalisa dan dirumuskan melalui penelitian. Oleh sebab itu harapan penulis model penggembalaan seperti ini dapat dikontribusikan kepada Gembala sidang dengan tujuan sebagai bahan acuan penataan pelayanan kedepan yang lebih baik yaitu untuk menerapkan pengaruh pemahaman penggembalaan yang sehat menurut kitab Titus terhadap pertumbuhan jemaat GPSI Wilayah I Samarinda

\section{MANFAAT PENELITIAN}

Adapun Manfaat penulisan ini sebagaimana yang diharapkan oleh penulis yaitu Pertama: agar dapat dipergunakan dalam mengembangkan pertumbuhan kerohanian yang sehat terhadap pertumbuhan jemaat lokal di Gpsi Wiayah I Kedua: agar menjadi bahan masukan bagi Gembala sidang bahwa 
betapa pentingnya penggembalaan yang sehat menurut kitab Titus terhadap pertumbuhan Jemaat lokal.

\section{PEMBATASAN PENELITIAN}

Penulis memberi batasan untuk penelitian ini agar terarah dan kesimpulan yang lebih akurat, maka penulis merasa perlu membuat pembatasan masalah supaya sesuai dengan judul yang telah penulis pilih yaitu "penggembalaan yang sehat menurut kitab Titus dan relevansinya terhadap pertumbuhan Jemaat GPSI Wilayah I " berdasarka surat penggembalaan Titus 1-3.

Sebagai sampel relepansinya bagi gereja masa kini maka penulis hanya berfokus pada jemaat GPSI Wilayah I , dengan harapan karya ilmiah ini dapat membantu setiap Gembala sidang didalam membina jemaat untuk bertumbuh secara kualitas maupun secara kuantitas. Sebab menjadi tanggung jawb seorang Gembala sidanglah semua jemaat yang di percayakan kepadanya untuk memberikan pengajaran yang sehat terhadap pertumbuhan iman dan kepastian keselamatan jemaat yang dibinanya.

\section{METODE PENELITIAN}

Metode penelitian yang dipakai dalam penelitian ini adalah metode deskriptif, analisis dan induktif yang dimaksud dengan metode induktif adalah metode yang bersifat menggambarkan, menguraikan sesuatu hal menurut apa adanya''[6] Penulis akan menguraikan dan menjelaskan setiap garis besar dalam tulisan ini, sesuai dengan konsep Alkitab dan didukung oleh buku-buku lain. Pada karya tulis ini penulis menggunakan metode analisis. Analisis adalah bersifat menguraikan''[7] penulis mengangkat nats Alkitab yang terdapat dalam Titu 1-3. Dan menganalisanya dengan menggunakan bahasa Asli, mengeksposisi nats tersebut serta menggunakan metode penafsiran Alkitab yang baik, yaitu secara literal, dan menguraikan secara satu persatu.

Metode induktif adalah bersifat induksi yaitu dilakukan dengan cara "penyempurnaan, penalaran untuk mencapai suatu kesimpulan." penalaran dan kesimpulan yang di ambil tentu didasarkan pada Alkitab sebagai sumber utama, baik Alkitab dalam bahasa Indonesia maupun dalam bahasa yunani. Penulis mempelajari Alkitab yang diangkat kemudian menyajikan sesuaidengan kebenaran. Selain itu penulis mengadakan riset terhadap buku-buku referensi untuk mengumpulkan fakta-fakta yang dibutuhkan dalam melengkapi penulisan tesis ini.

Selanjutnya penulis menggunakan metode deskripsi dan analisis yaitu dengan mendefenisikan arti penggembalaan dan pertumbuhan dalam bahasa Indonesia, dan dalam bahasa yunani sebagai bahasa asli penjanjian baru. Apa yang menjadi tujuan penting dalam penggembalaan dan dalam pertumbuhan

Dengan menggunakan metode deskripsi dan riset kepustakaan untuk mengumpulkan data yang berkaitan dengan pengaruh pemahaman penggembalaan yang sehat terhadap pertumbuhan jemaat menurut surat Titus 1-3. Penulis menggali satu persatu arti dan makna dari setiap kata yang tercantum dalam nats ini. Dari bahasa asli dan pengertian yang sederhana menurut bahasa Indonesia untuk menemukan arti sesungguhnya dan mudah diterapkan dalam hidup penggembalaan. Penulis menguraikan penelitian ini dalam bentuk penerapan dalam kehidupan sehari-hari bagi orang percaya. Penerapan ini menjelaskan tentang pengertian secara realistis dan desertai dengan contohcontoh yang praktis.

\section{KESIMPULAN}

Penulis memberikan kesimpulan terhadap pembahasan ini, diharapkan dengan adanya kesimpulan ini akan mempermudah untuk mengerti dan memahami prinsip-prinsip "Pengaruh penggembalaan yang sehat terhadap pertumbuhan jemaat berdasarkan Titus 1-3" secara mendalam.

Berdasarkan tabel rangkuman kecenderungan kepedulian penggembalaan diatas diketahui bahwa kepedulian penggembalaan berada pada tinggi $(44.39 \%)$ ke sangat tinggi (33.27\%). namun demikian, katagori sedang kerendah dan sangat rendah berjumlah $21,8 \%$. Jumlah ini merupakan jumlah yang besar karena lebih dari seperemat subyek memandang kepedulian gembala kurang baik.

Berdasarkan tabel rangkuman kecenderungan keteladanan penggembalaan diatas diketahui bahwa keteladanan penggembalaan berada 
pada tinggi (43.81\%) ke sangat tinggi (30.10 $\%)$. namun demikian, katagori sedang kerendah dan sangat rendah berjumlah 26,8\%. Jumlah ini merupakan jumlah yang besar karena lebih dari seperemat subyek memandang keteladanan gembala kurang baik.Berdasarkan tabel rangkuman kecenderungan kecakapan penggembalaan diatas diketahui bahwa kecakapan penggembalaan berada pada tinggi $(71.70 \%)$ ke sangat tinggi $(17.30 \%)$.Berdasarkan tabel rangkuman kecenderungan karakter penggembalaan diatas diketahui bahwa karakter penggembalaan berada pada tinggi $(47.86 \%)$ ke sangat tinggi (23.72\%).namun demikian, katagori sedang kerenda dan sangat rendah berjumlah 26,51\%. Jumlah ini merupakan jumlah yang besar karena lebih dari seperempat subyek memandang karakter gembala kurang baik.

Dari hasil penelitian, maka dapat diambil kesimpulan sebagai berikut:

Pertama: Pelayanan penggembalaan adalah suatu pelayanan yang sangat vital dalam Gereja, pelayanan penggembalaan memegang peranan yang sangat penting di dalam pertumbuhan sebuah gereja. Maka salah satu tanda bahwa sebuah gereja bertumbuh dapat diukur dengan bagaimana kualitas penggembalaan yang dilakukan Gembala terhadap komunitas yang sedang digembalakannya.

Apa bila pelayanan penggembalaan yang dimiliki sebuah gereja kuat, maka dapat dipastikan bahwa gereja akan bertumbuh menjadi kuat. Sebaliknya apa bila pelayanan penggembalaan di dalam sebuah gereja lemah, maka dapat diprediksi bahwa gereja akan menjadi lemah dan tidak dapat bertumbuh sebagai mana yang diharapkan.

Ibarat seorang anak yang membutuhkan perhatian yang optimal dari orangtuanya agar dia kelak akan bertumbuh dengan sehat, demikian pula gembala terhadap jemaat.

Surat Titus adalah surat penggembalaan yang dikirim oleh Paulus, surat ini ditulis dan dikirim ke pulau Kreta karena di pulau Kreta muncul pengajaran pengajaran yang berlawanan dengan pengajaran Kristen. Yang disebut pengajaran sesat.

Pengajaran sesat ini menaruh perhatian pada masalah dongeng dan silsilah silsilah. Pengajaran ini membawa orang kepada perbuatan tidak suci. Paulus menasihati Titus untuk melawan pengajaran yang keliru itu dengan cara menyampaikan pengajaran yang benar dan tingkah laku Kristen yang sejati.

Paulus juga menekankan tugas dan tanggung jawab mereka sebagai pemimpin Kristen yang benar.

Di tengah tengah umat Kristen yang dikacaukan oleh pengajaran pengajaran sesat, diperlukan pengaturan yang baik untuk membuka topeng pengajaran yag sesat dan menjamin bahwa pengajaran yang benar tetap terpelihara dan dilindungi dari segala penyelewengan.

Oleh sebab itu dalam surat ini ditekankan masalah penggembalaan untuk menjaga agar pengajaran disampaikan dengan benar dan ditanamkan dengan teguh dalam kehidupan umat Kristen.

Pertanyaan dalam penelitian ini adalah pengaruh penggembalaan yang sehat terhadap pertumbuhan jemaat GPSI Wilayan I sesuai kitab Titus sudah terjawab dengan kesimpulan ada pengaruh penggembalaan yang sehat terhadap pertumbuhan jemaat GPSI Wilayah I. pengaruh penggembalaan yang sehat mampu memberi sumbangan efektif terhadap pertumbuhan jemaat GPSI Wilayah

\section{KEPUSTAKAAN}

[1]. Ralph M.Riggs,Gembala sidang yang berhasil(Malang:Gandummas,1948)

[2]. Seth Msweli dan Donal,Gembala sidang dan pelayanannya,( Bandung:Kalam hidup 1974)

[3]. Priskila Paksoal, Peny, Buku pedoman kehidupan yang dinamis:Dinamika dasar One to one, (Bekasi: Dinamyc Churches Internastional Indonesia), 1991

[4]. Seth Msweli dan donal, Gembala sidang dan pelayanannya (Bandung: Kalam hidup 1974)

[5]. Ronald W.leigh, Melayani dengan Efektif (Jakarta: Bpk Gunungmulia,1991)

[6]. Widodo, “deskriptif”dalam kamus Ilmiah popular(Yogyakarta: absolute,2002), 
[7]. Widodo, "analisis"dalam kamus Ilmiah popular (Yogyakarta:Absolut,2002)

[8]. Alkitab, Lembaga Alkitab Indonesia, 1974.

[9]. Abineno, (1987) Jemaat.Jakarta: BPK Gunung Mulia).

[10]. Arichea Daniel C dan Howard A. Hatton, 2004, pedoman penafsiran Alkitab.

[11]. Anggraito Noor,2012, Rahasia dibalik Gembala dan Domba, Yogyakarta, Andi Offset.

[12]. Alwi Hasan, dkk,2003, Kamus Besar Bahasa Indonesia,Jakarta: balaipustaka,203.

[13]. Barclay William , 2001,Pemahaman Alkitab Setiap Hari, Jakarta, BPK Gunung Mulia.

[14]. Bartlett David L, 2003 "Pelayanan Dalam Perjanjian Baru” Jakarta BPK Gunung Mulia.

[15]. Bartlett David L, 2003 "Pelayanan Dalam Perjanjian Baru” Jakarta BPK Gunung Mulia.

[8] Bailey,Brian, (2004) menuju kemuliaan,Jakarta:Voice of hope.

[9] Bergant, Dianne C.S.A \& Robert J.Karris, 1989, OFM, Tafsir Alkitab Perjanjian Baru.

[10] Blaiklock E.M, , 1981,Surat-Surat Penggembalaan, Malang: Gandum Mas.

[11] Brauch Mant fred T, 2003, ucapan Paulus yang sulit,Malang seminari Alkitab Asia Tenggara Bair P. A, 1997,Ensiklopedi Alkitab Masakini jilid II M-Z JakartaYayasan Komunikasi Binakasi/ OMF.

[12] Bartlett J.V, 1946, Ensiklopedi Alkitab Masakini jilid 1 dari A-L Jakarta, yayasan komunikasi Bina kasih/OMF.

[13] Cole Steven J. Qualifed Elders ( Titus 1 : 6-8) hal 14. www.bible.org. di unduh 24 Juni 2011.

[14] Canada David,2015, spritual leadership,seri:pelayanan di Gereja Kecil perintisan \& kelompok sel, Malang:Gandum Mas
[15] Conner, Kevin J. 2004 "Jemaat dalam Perjanjian Baru” Malang, Gandum Mas, 239.

[16] Cowles Robert,1977, Gembala sidang, Bandung, Yayasan Kalam hidup,10

[17] Daniel Arichei C dan Howard A.Hatton, 2004 , Pedoman penafsiran Alkitab surat-surat Paulus kepada Tomotius dan kepada Titus, Jakarta, Yayasan Karunia

[18] Dufour Xavier- Ensiklopedi Perjanjian baru,Yogyakarta:kanisius, 1990,238-239.

[19] E Beyreuther,1973,„Ensiklopedi Alkitab Masa Kini jilid 1 A-L,Jakarta:Yayasan Komunikasi Binakasi/OMF,330.

[20] Fances. Eddy, 1993, Bertumbuh menuju kesempurnaan, Yokyakarta:Yayasan Andi.

[21] Faot, Agustinus, Jonathan Octavianus, and Juanda Juanda. "Kematian Bukan Akhir Dari Segalanya." Journal Kerusso 2.2 (2017): 15-30.

[22] Graham Ryken Philip. 2007, "I Timothy: Reformed Expository Commentary" New Jersey: P\&R Publishing. 111

[23] George, Denise, 2015,Gembala ideal Bagi jemaat, Malang Gandum Mas.

Hananiel Nugroho, 2002,Alkitab penuntun hidup berkelimpahan,Malang Gandum Mas, 2024

[24] Hadiwijono Harun, 1992, Iman Kristen, Jakarta: Bpk Gunung Mulia,40

[25]Henry,Matthew,1991,Commentar"Massac husetts, Hendrickson Publishers, 656

[26] Juanda J. Pengaruh Kelas Pendalaman Iman Anak Lebak Arum (Piala) Terhadap Pertumbuhan Rohani Anak Usia 11-14 Tahun Di Kompleks Perumahan Lebak Arum Surabaya. Journal Kerusso. 2016 Mar 23;1(1):51-6.

[27] Keathley J. Hampton,2016 III. Instruction Concerning Elders In The Church ( 1 Titus 1:5-8) Hal. 48. www.bible.org. Di unduh 24 Juni 
[28] Leigh, Ronald W. 2011, Melayani dengan Efektif, Jakarta Gunungmulia,89.

[29] London J.R.H.B.Neil B.wiseman, 1994, Pelayan Allah yang berjiwa besar, judul asli The Hear of A Gret Pastor, pen:A.J.Syauta Jakarta: Yayasan Pekabaran Injil "IMMANUEL,355

[30] Lawson Leroy, 1985 Gereja Perjanjian baru dahulu \& sekarang,Surabaya,Yakin, 197.

[31] Msweli Seth dan Donald Crider,1974, Gembala Sidang dan pelayanannya, Bandung, Kalam hidup, 196

[32] Moor, Beth, 2004 Hidup adalah Kristus mendalami kerinduan Paulus, peny: Ostaria silaban.Batam center"Gospel pres, 147-148.

[33] Maxwell John C,2002, 21 menit paling bermakna dalam hari-hari pemimpin sejati, pen. Arvin saputra, Batam,Interaksa,187

[34] Montgomery Boice.James, 2011, dasardasar Iman Kristen, judul asli, Foundations of the Cristian Faith,Surabaya,Momentum,463.

[35] M. Bons-storm, Apakah penggembalaan itu?,(Jakarta: Gunungmulia,1997)4.

[36] Morris Leon, 1986, Teologi Perjanjian Baru, judul asli, New Testament Theologi, Copyright, ,449

[37] Maryono, Petrus, 2001,Hukum torat dan Pembenaran, Yogya, STTII Pistis, vol.1.no 1,34

[38] Newton Phil A, 2005, Elders in Congregational Life ,Grand Rapids, Kregel Publications, 5

[39] Prasetyo, Widi, et al. "Measuring the Quality of God's Servants According to Acts 6: 3 At the Surabaya City Tabernacle Pentecostal Church." Journal KERUGMA 2.1 (2019): 2433.

[40] Prince.Derek,1995, Bertobat dan Percaya seri 2,Judul asli Repent and Believe, pen Peter

[41] Prince, Derek, 1994, membangun jemaat Kristus,Jakarta, Yayasan pekabaran Injil Immanuel
[42] Pettry W.Ernest,1983, Berkhotbah \& mengajar,Judul asli Preaching and

[43] Poerwadarminta W.J.S, 2006, kamus umum bahasa Indonesia,Jakarta,balai pustaka, 964 .

[44] Rim Yeremia, 1995, Iman yang hidup \& Berkuasa, Yokyakarta Yayasan ANDI,4

[45] Rienecker. Fritz, 1980,A Linguistic Key to the Greek New Testament

[46] Rumiyati, Rumiyati, et al. "Pengaruh Kepemimpinan Hamba Tuhan Dalam Pertumbuhan Kerohanian Jemaat Gereja GPdI 'Zion'Krebet, Tembalang, Wlingi-Blitar." Journal Kerusso 3.2 (2018): 9-19.

[47] Strauch, Alexander. (1994) The New Testament Deacon:The Church`s Minister of Merrcy

[48] Senduk H L, 1989, Kedwasaan Rohani, Jakarta,Yayasan Betlehem Indonesia, 29

[49] Strauch ,Alexander,( 1999 )"Kepenatuaan atau Kependetaan”Yogyakarta: ANDI,) v

[50] Schwarz ,Christian A, 1998, Pertumbuhan gereja yang Alami: delapan kualitas EsensialBagi sebuah gereja yang sehat,Jakarta:Metanoia,

[51] Stamps Donald C,1994. "Alkitab Penuntun Hidup Berkelimpahan"(Malang: Gandum Mas,

[52] Santoso Hasan,Perjanjian Baru Interlinear, Yunani- Indonesia dan Konkordansi Perjanjian Baru (PBIK) Jilid I,1143

[53] Stott, John R.W, 1997 "The Message of Timothy \& Titus" England: Inter-Varsity Press.

[54] Stoott.John R.W, 2003, seri pemahaman amanat alkitab masakini EFESUS, judul asli The message of Ephesians The Bible Speaks Today, (Jakarta:Yayasan Komunikasi. 
KERUSSO, VOLUME 4 NUMBER 2 SEPTEMBER 2019

[55] Sanders. J. Oswald, 1979 "Kepemimpinan Rohani” Bandung: Kalam Hidup.

[56] Spittler Russell P. 1988,Pertama \& kedua Korintus, $\mathrm{M}$ 